Article

\title{
TmAtg6 Plays an Important Role in Anti-Microbial Defense Against Listeria monocytogenes in the Mealworm, Tenebrio molitor
}

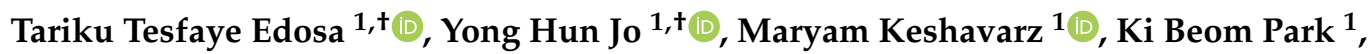 \\ Jun Ho Cho ${ }^{1}$, Young Min Bae ${ }^{1}$, Bobae Kim ${ }^{1}$, Yong Seok Lee ${ }^{2} \mathbb{D}$ and Yeon Soo Han ${ }^{1, * \mathbb{C}}$ \\ 1 Department of Applied Biology, Institute of Environmentally-Friendly Agriculture (IEFA), College of \\ Agriculture and Life Sciences, Chonnam National University, Gwangju 61186, Korea; \\ bunchk.2000@gmail.com (T.T.E.); yhun1228@jnu.ac.kr (Y.H.J.); mariakeshavarz1990@gmail.com (M.K.); \\ misson112@naver.com (K.B.P.); junhojo12@naver.com (J.H.C.); ugisaka@naver.com (Y.M.B.); \\ kbb941013@gmail.com (B.K.) \\ 2 Department of Life Science and Biotechnology, College of Natural Sciences, Soonchunhyang University, \\ Asan City 31538, Korea; yslee@sch.ac.kr \\ * Correspondence: hanys@jnu.ac.kr; Tel.: +82-62-530-2072 \\ + These authors contributed equally to this work.
}

Received: 25 October 2019; Accepted: 8 February 2020; Published: 12 February 2020

\begin{abstract}
Autophagy-related gene-6 (Beclin-1 in mammals) plays a pivotal role in autophagy and is involved in autophagosome formation and autolysosome maturation. In this study, we identified and characterized the autophagy-related gene-6 from Tenebrio molitor (TmAtg6) and analyzed its functional role in the survival of the insect against infection. The expression of TmAtg6 was studied using qRT-PCR for the assessment of the transcript levels at various developmental stages in the different tissues. The results showed that $\operatorname{TmAtg} 6$ was highly expressed at the 6-day-old pupal stage. Tissue-specific expression studies revealed that $\operatorname{TmAtg} 6$ was highly expressed in the hemocytes of late larvae. The induction patterns of TmAtg6 in different tissues of T. molitor larvae were analyzed by injecting Escherichia coli, Staphylococcus aureus, Listeria monocytogenes, or Candida albicans. The intracellular Gram-positive bacteria, L. monocytogenes, solely induced the expression of TmAtg6 in hemocytes at 9 h-post-injection, whilst in the fat body and gut, bimodal expression times were observed. RNAi-mediated knockdown of the TmAtg6 transcripts, followed by a challenge with microbes, showed a significant reduction in larval survival rate against $L$. monocytogenes. Taken together, our results suggest that TmAtg6 plays an essential role in anti-microbial defense against intracellular bacteria.
\end{abstract}

Keywords: TmAtg6; induction pattern; autophagy; intracellular bacteria; RNAi

\section{Introduction}

Macroautophagy (autophagy) collectively refers to a group of intracellular degradation pathways that mediate the breakdown of intracellular material in lysosomes [1,2]. It is an evolutionarily conserved, catabolic process associated with multiple biological and physiological processes. Besides, it performs protective and defensive functions with respect to innate immunity, inflammation, and resistance against microbial infection [3,4].

The process of autophagy extends from autophagosome formation to the degradation of non-self, damaged, or surplus cell components by lysosomal hydrolases via a series of steps $[5,6]$. In selective autophagy, the specific cargos are first tagged by ubiquitination and recognized by the autophagy adaptor molecules for subsequent targeting to autophagosomes for degradation [7]. The selective autophagy mainly targets misfolded proteins, damaged organelles, and intracellular pathogens like 
Mycobacterium spp., Salmonella spp., and Listeria spp. [8]. Based on the cargo being delivered for degradation, xenophagy is the cargo that contains intracellular pathogens [8]. Therefore, in xenophagy, pathogen-containing phagosomes are exclusively targeted for autophagic degradation [9]. In either no-selective or selective autophagy, various autophagy-related genes are involved in different stages of autophagy (initiation, phagophore formation, elongation, and completion) [10].

In yeast, where the majority of the molecular mechanisms of autophagy have been studied, the Atg1 kinase complex with Atg13 and Atg17 induces membrane isolation and initiates autophagy [11,12]. The phosphatidylinositol (PtdIns) 3-kinase complex (complex I: Vps15-Vps34-Vps30/ Atg6-Atg14; and complex-II: Vps15-Vps34-Vps30/Atg6-Atg14-Vps38) [13,14] and Atg9 complex [15] affect phosphoinositides to recruit proteins for phagophore and autophagosome formation. Finally, the ubiquitin-like protein conjugation complexes (Atg8, Atg12, Atg4, Atg7, and Atg3, among other proteins) elongate and complete the autophagy process [16]. The roles of TmAtg3, TmAtg5, and TmAtg8 in mediating the autophagy-based clearance of Listeria in T. molitor have been investigated previously $[17,18]$.

Atg6 (Beclin-1 in mammals) is highly conserved between yeast and mammals. It plays a pivotal role in autophagy and is involved in autophagosome formation and autolysosome maturation by forming a complex with Vps34, Vps15, UVRAG, and Vps38 [19].

Atg6 is relatively unique since it is not only autophagy-specific, but also has different functions; for example, the Atg6/Vps30 complex is required for autophagy, sorting vacuolar contents [20], and pollen germination [21], and acts as a tumor suppressor gene [22,23]. Therefore, biologically, Atg6 is required for life span extension in both animals and plants in supplying the cells with energy under adverse conditions, maintaining critical levels of metabolism, and clearing microbial infections. However, the molecular function of Atg6 in T. molitor has not yet been studied. Thus, we sought to identify the function of Atg6 in T. molitor with respect to the molecular mechanism of autophagy during microbial infection in beetles. Therefore, in this study, we characterized the role of TmAtg6 in insect survivability against bacterial challenge using RNAi gene silencing. We demonstrated that TmAtg6 has a specific molecular function in the immune response against the intracellular bacteria, L. monocytogenes.

\section{Results}

\subsection{Sequence Identification and In Silico Analysis of TmAtg6}

Full-length cDNA sequence of TmAtg6 was obtained from the T. molitor RNAseq database and 5'/ 3'-RACE PCR. TmAtg 6 contains an open reading frame (ORF) of $1161 \mathrm{bp}$ that encodes a protein of 386 amino acid residues (Figure 1). The $5^{\prime}$ - and $3^{\prime}$-untranslated regions (UTR) of TmAtg6 were 105 and $348 \mathrm{bp}$ in length, respectively. The poly (A) signal (AATAAA) was found $9 \mathrm{bp}$ upstream of the poly (A) tail. The multiple alignments of TmAtg6 amino acid sequence with its orthologs indicates a high degree of conservation in the Atg6 amino acid sequence within insects (Figure 2A). The phylogenetic analysis revealed Coleopteran insects (Asbolus verrucosus beclin-1-like protein and Tribolium castaneum Beclin-1-like protein) grouped together (Figure 2B). Furthermore, the percentage of identity showed that TmAtg6 is closest to Tribolium castaneum (TcBeclin-1) since they share the highest sequence identity (89\%) (Figure S1). 
AT GGG GAT GAC ATG ATC ATC TGT TAA ACG CCA AAC AAC GAT TAC AAA AGA AGT CTA TTT ATT TGT GAT AAA TTC GCG GAA GAA TAT GTG AGT CAT AGT GCA AAA ATG GCC GAg GAT AAA AGT GAg AAA ATG TTG AtA TCA TTT ATG TGC CAA AGg TGT TCA CAA 60 $\begin{array}{lllllllllllllllllllll}M & \mathrm{~A} & \mathrm{E} & \mathrm{D} & \mathrm{K} & \mathrm{S} & \mathrm{E} & \mathrm{K} & \mathrm{M} & \mathrm{L} & \mathrm{I} & \mathrm{S} & \mathrm{F} & \mathrm{M} & \mathrm{C} & \mathrm{Q} & \mathrm{R} & \mathrm{C} & \mathrm{S} & \boldsymbol{Q} & 20\end{array}$ CCT TTA CAg TTG GAT GAT TCT TTG AGC TCA TTC AGT GAA CAT ATT TCA GCA GAg CTA AAC 120 $\begin{array}{lllllllllllllllllllll}P & \mathrm{~L} & Q & \mathrm{~L} & \mathrm{D} & \mathrm{D} & \mathrm{S} & \mathrm{L} & \mathrm{S} & \mathrm{S} & \mathrm{F} & \mathrm{S} & \mathrm{E} & \mathrm{H} & \mathrm{I} & \mathrm{S} & \mathrm{A} & \mathrm{E} & \mathrm{L} & \mathrm{N} & \mathbf{4}\end{array}$ TTA CCG ATA CAT TCC AAT CCA GAC GTA GAT TTA GAA TCT CAA GCA ACT AGT TTC GAT CAT 180 $\begin{array}{lllllllllllllllllllll}\mathrm{L} & \mathrm{P} & \mathrm{I} & \mathrm{H} & \mathrm{S} & \mathrm{N} & \mathrm{P} & \mathrm{D} & \mathrm{V} & \mathrm{D} & \mathrm{L} & \mathrm{E} & \mathrm{S} & \mathrm{Q} & \mathrm{A} & \mathrm{T} & \mathrm{S} & \mathrm{F} & \mathrm{D} & \mathrm{H} & 60\end{array}$ TAC ATA GCT CCA TGT CGT TTG TTC GAT TCT GGA AAT GGC TTC ATG TTA ATA TCG GAT GGG 240 $\begin{array}{lllllllllllllllllllll}\mathrm{Y} & \mathrm{I} & \mathrm{A} & \mathrm{P} & \mathrm{C} & \mathrm{R} & \mathrm{L} & \mathrm{F} & \mathrm{D} & \mathrm{S} & \mathrm{G} & \mathrm{N} & \mathrm{G} & \mathrm{F} & \mathrm{M} & \mathrm{L} & \mathrm{I} & \mathrm{S} & \mathrm{D} & \mathrm{G} & 80\end{array}$

AAT GAA GTA GAT TCA TTA AGT CAC ATA TAT AAA AGA AAA GCA GCT TTA TTC GAT ACT CTC 300

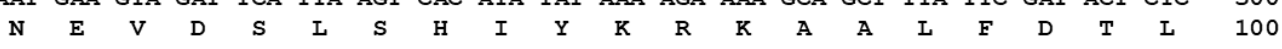

TCA GGC AAC TCA AAC ATT GAC CAC CCT TTG TGT GAT GAA TGT ACG GAT TAT TTA ATA GAA 360 $\begin{array}{lllllllllllllllllllll}\mathrm{S} & \mathrm{G} & \mathrm{N} & \mathrm{S} & \mathrm{N} & \mathrm{I} & \mathrm{D} & \mathrm{H} & \mathrm{P} & \mathrm{I} & \mathrm{C} & \mathrm{D} & \mathrm{E} & \mathrm{C} & \mathrm{T} & \mathrm{D} & \mathrm{Y} & \mathrm{L} & \mathrm{I} & \mathrm{E} & 120\end{array}$

ATT TTA GAA CAA GAA TTA GCT GAC ACA CAA AAT GAT TAT GAT GAT TAC CTC AGA TAT TAT 420 $\begin{array}{lllllllllllllllllllll}I & \mathrm{~L} & \mathrm{E} & \mathrm{Q} & \mathrm{E} & \mathrm{L} & \mathrm{A} & \mathrm{D} & \mathrm{T} & \mathrm{Q} & \mathrm{N} & \mathrm{D} & \mathrm{Y} & \mathrm{D} & \mathrm{D} & \mathrm{Y} & \mathrm{L} & \mathrm{R} & \mathrm{Y} & \mathrm{Y} & 140\end{array}$

AAG ATG CTT CAA AAT GAT ACA AAT GAG CTG AAg ATT GGT GAA CTA GAA AAA GAA TTA GAT 480 $\begin{array}{lllllllllllllllllllll}\mathrm{K} & \mathrm{M} & \mathrm{L} & \mathrm{Q} & \mathrm{N} & \mathrm{D} & \mathrm{T} & \mathrm{N} & \mathbf{E} & \mathrm{L} & \mathrm{K} & \mathrm{I} & \mathrm{G} & \mathrm{E} & \mathrm{L} & \mathrm{E} & \mathrm{K} & \mathrm{E} & \mathrm{L} & \mathrm{D} & 160\end{array}$

GAT TTG AAA GCT GAA GGA AAT CGA TTT CTA GAA GAG TTG GAA GCT TTA AAG AAA GAA GAA 540 $\begin{array}{lllllllllllllllllllll}\mathrm{D} & \mathrm{L} & \mathrm{K} & \mathrm{A} & \mathrm{E} & \mathrm{G} & \mathrm{N} & \mathrm{R} & \mathrm{F} & \mathrm{L} & \mathrm{E} & \mathrm{E} & \mathrm{L} & \mathrm{E} & \mathrm{A} & \mathrm{L} & \mathrm{K} & \mathrm{K} & \mathrm{E} & \mathrm{E} & 180\end{array}$

ATT GAG TTG CAA AAT GCT ATT GAA GAG CAA GAA TCA GTA GCT AGG AGA CTT GAC CGT GAA 600 $\begin{array}{llllllllllllllllllllll}I & E & L & Q & N & A & I & E & E & Q & E & S & \text { V } & \text { A } & \text { R } & \text { R } & \text { L } & \text { D } & \text { R } & \text { E } & 200\end{array}$

CGT CAG ATT TAC TAC AAA GAG TAC ACA AAG CAT CAG AAA AAT TAT ATG CAA GCT TGT GAG 660 $\begin{array}{lllllllllllllllllllll}R & Q & I & Y & Y & K & E & Y & T & K & H & Q & K & N & Y & M & Q & A & C & E & 220\end{array}$

GAT GCA CAG AGC TTG GAG TGC CAG CTC AAT TAT ACA CAG ATG CAA CTG GAT AAA TTG AAG 720 $\begin{array}{llllllllllllllllllllll}\mathrm{D} & \mathrm{A} & \& & \mathrm{~S} & \mathrm{~L} & \mathrm{E} & \mathrm{C} & \mathrm{Q} & \mathrm{L} & \mathrm{N} & \mathrm{Y} & \mathrm{T} & \mathrm{Q} & \mathrm{M} & \mathrm{Q} & \mathrm{L} & \mathrm{D} & \mathrm{K} & \mathrm{L} & \mathrm{K} & 240\end{array}$

AAG ACT AAT GTT TTC AAT GCA ACT TTT CAC ATA TGG CAC AAA GGT CAC TTT GGT ACC ATT 780 $\begin{array}{lllllllllllllllllllll}\text { K } & \text { T } & \text { N } & \text { V } & \text { F } & \text { N } & \text { A } & \text { T } & \text { F } & \text { H } & \text { I } & \text { W } & \text { H } & \text { K } & \text { G } & \text { H } & \text { F } & \text { G } & \text { T } & \text { I } & 260\end{array}$

AAT AAT TTC TGC TTG GGA CGC CTT CCT TCA GCA CCT ATA GAT TGG TCA GAA ATT AAT GCA 840 $\begin{array}{lllllllllllllllllllllll}\text { N } & \text { N } & \text { F } & \text { C } & \text { L } & \text { G } & \text { R } & \text { L } & \text { P } & \text { S } & \text { A } & \text { P } & \text { I } & \text { D } & \text { W } & \text { S } & \text { E } & \text { I } & \text { N } & \text { A } & 280\end{array}$ GCC TGG GGT CAG ACT GCT CTG TTG CTC TCT GCT CTT GCA CGT AAA ATA AAT CTA ACT TTT 900 $\begin{array}{llllllllllllllllllllll}\text { A } & \text { W } & \text { G } & Q & \text { T } & \text { A } & \text { L } & \text { L } & \text { L } & \text { S } & \text { A } & \text { L } & \text { A } & \text { R } & \text { K } & \text { I } & \text { N } & \text { L } & \text { T } & \text { F } & 300\end{array}$ GAA AGA TAT CGA TTA GTT CCA TAT GGC AAT CAT TCA TAC ATT GAG GTT ATT GGT GAA CAA 960 $\begin{array}{llllllllllllllllllllll}\mathbf{E} & \mathrm{R} & \mathrm{Y} & \mathrm{R} & \mathrm{L} & \mathrm{V} & \mathrm{P} & \mathrm{Y} & \mathrm{G} & \mathrm{N} & \mathrm{H} & \mathrm{S} & \mathrm{Y} & \mathrm{I} & \mathrm{E} & \mathrm{V} & \mathrm{I} & \mathrm{G} & \mathrm{E} & \mathrm{Q} & 320\end{array}$ AAG GAG TAT CCA CTG TAT GGA TCC GGA GGA TTC AAG TTT CTT TGG GAT ACA AAG TTT GAT 1020 $\begin{array}{lllllllllllllllllllll}\text { K } & \text { E } & \text { Y } & \text { P } & \text { L } & \text { Y } & \text { G } & \text { S } & \text { G } & \text { G } & \text { F } & \text { K } & \text { F } & \text { L } & \text { W } & \text { D } & \text { T } & \text { K } & \text { F } & \text { D } & 340\end{array}$ AAT GGA ATG GCG CTT TTT TGG ATT GTT TGC AAC AAT TCC AAG AGA AAG TCC AGA AAT TGG 1080 $\begin{array}{lllllllllllllllllllllll}\text { N } & \text { G } & \text { M } & \text { A } & \text { L } & \text { F } & \text { W } & \text { I } & \text { V } & \text { C } & \text { N } & \text { N } & \text { S } & \text { K } & \text { R } & \text { K } & \text { S } & \text { R } & \text { N } & \text { W } & 360\end{array}$

AAA AGg GCA ACA AGC AAT TCT GTT TTC CTT ACA GAA CAA ATA AAg GAA AAA TCG AGg ATA 1140

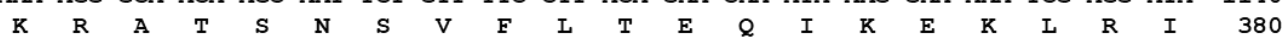
ATG ATG CAA GCT ACT CTA TAA $\begin{array}{llllll}M & \mathrm{M} & \mathrm{Q} & \mathrm{A} & \mathrm{L} & \\ & & \end{array}$

AGA TAC AGC TGA ATT CTG AAG AAC AAT GGA CCA AAG CCA TGA AAT TCA TGT TAA CCA ATT TGA AAT GGG GTT TAG CTT GGA TTT CAT CCC AGT TAA ATA GTA TAG GTA TAG ATG AAC ATA TGC AAA TAG AAA ATT AGT GTC ATT GAA TGT TTA GTA TTT TTT ATA TAT TTA AGT AAA TTA TAG TAC CTA CAA ATA AGT TAT ATC AAT ACC ATA TTT TTG TTA TGA AAA TGA CTG ACT TTG TTG TAA TTA TGT TTA ATA AAT TAG CGA CAG ACA AAA AAA AAA AAA AAA AAA AAA AAA AAA AAA AAA AAA AAA AAA AAA AAG AAA AAA AAA AAA AAA AAA AAA AAA AAA

Figure 1. Nucleotide and deduced amino acid sequences of TmAtg6. The full-length open reading frame (ORF) sequence of TmAtg6 gene was identified. TmAtg6 has $1161 \mathrm{bp}$ of ORF encoding 386 amino acid (aa) residues. Domain analysis indicates that TmAtg6 contains one Atg6 domain. The polyadenylation signal sequence (AATAA) is underlined in the $3^{\prime}$-UTR region and the $\operatorname{TmAtg} 6$ domain is shaded in orange. 


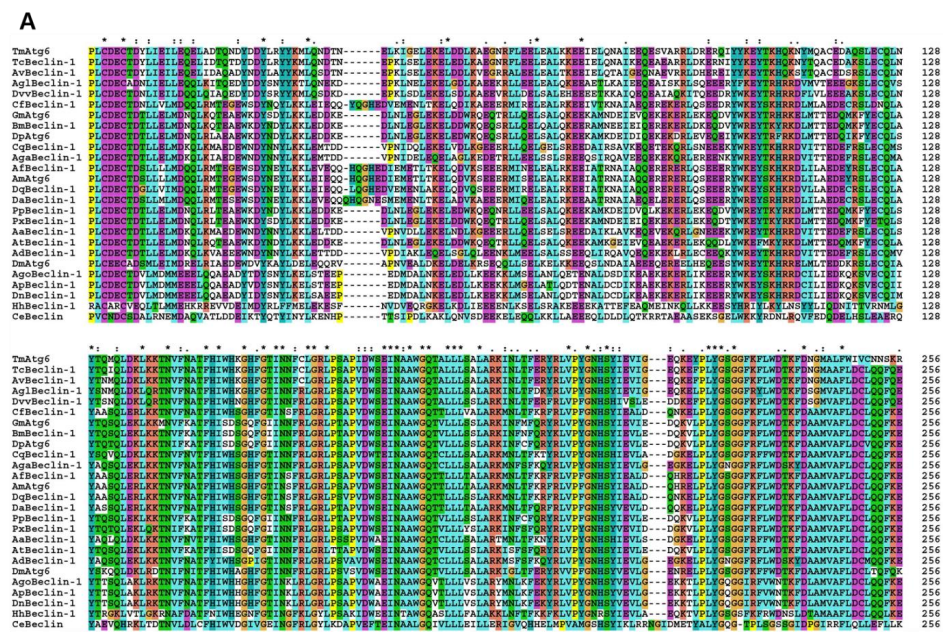

B

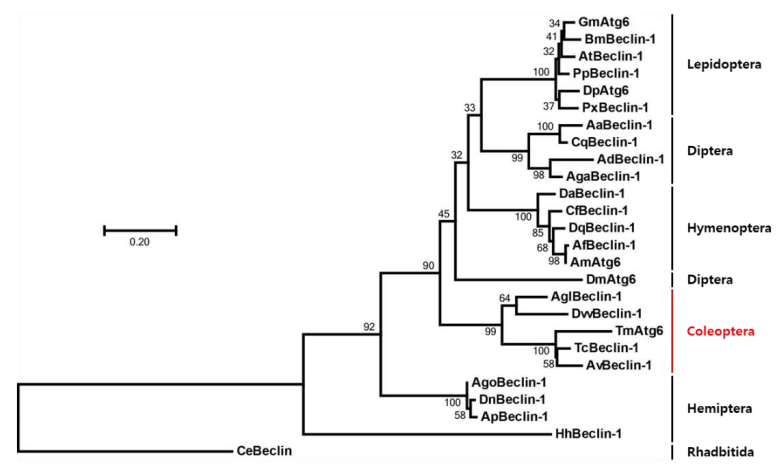

Figure 2. Multiple alignments and molecular phylogenetic analysis of insect beclin-1 homologs protein. (A) Multiple sequence alignment of TmAtg6 along with its homologs. The highly conserved beclin-1 domain was aligned by using Clustal X2 software. The symbols indicate conservation scores between groups according to the Gonnet PAM 250 matrix (“*'> ' ${ }^{\prime}>>^{\prime}$. ') and '-' indicates internal or terminal gaps. (B) Phylogenetic analyses of TmAtg6 homologs were performed based on the multiple alignments using the Clustal X2 and the phylogenic tree was constructed by MEGA7 programs using the maximum likelihood and bootstrapped of 1000 replications. The red color text with vertical line used to indicate the coleopteran order grouped together. Phylogenetic analysis of the Caenorhabditis elegans beclin-1 sequence was used as the outgroup. The following protein sequences were used to construct the phylogenetic tree. TmAtg6 (Tenebrio molitor Autophagy-related 6), TcBeclin-1 (Tribolium castaneum Beclin-1-like protein; EFA06871.2), AvBeclin-1 (Asbolus verrucosus beclin-1-like protein; RZC37309.1), AglBeclin-1 (Anoplophora glabripennis beclin-1-like protein; XP_018570978.1), DvvBeclin-1 (Diabrotica virgifera beclin-1-like protein; XP_028144478.1), AgoBeclin-1 (Aphis gossypii beclin-1-like protein; XP_027849435.1), ApBeclin-1 (Acyrthosiphon pisum beclin-1-like protein; XP_016661093.1), HhBeclin-1 (Halyomorpha halys beclin-1-like protein; XP_014275231.1), DnBeclin-1 (Diuraphis noxia PREDICTED: beclin-1-like protein; XP_015372132.1), AaBeclin-1 (Aedes aegypti AAEL010427-PA; EAT37604.1)' AdBeclin-1 (Anopheles darling beclin-1; ETN63629.1), AgaBeclin-1 (Anopheles gambiae str. PEST AGAP003858-PA; EAA06006.4), CqBeclin-1 (Culex quinquefasciatus beclin-1 EDS35627.1), DmAtg6 (Drosophila melanogaster Autophagy-related 6; AAF56227.1), DpAtg6 (Danaus plexippus autophagy related protein Atg6; EHJ78273.1), GmAtg6 (Galleria mellonella autophagy related protein Atg6; AFP66875.1), PpBeclin-1 (Papilio polytes beclin-1-like protein; XP_013145468.1), PxBeclin-1 (Plutella xylostella beclin-1-like protein; XP_011559638.1), BmBeclin-1 (Bombyx mori autophagy related protein Atg6; ACJ46062.1), AtBeclin-1 (Amyelois transitella beclin-1-like protein XP_013199196.1), AfBeclin-1 (Apis florea beclin-1-like protein isoform X1; XP_003696795.1), AmAtg6 (Apis mellifera autophagy specific gene 6 isoform X2; XP_392365.1), DaBeclin-1 (Diachasma alloeum beclin-1-like protein isoform X1; XP_015116372.1), CfBeclin-1 (Camponotus floridanus beclin-1-like protein isoform X1; XP_011257589.1), DqBeclin-1 (Dinoponera quadriceps beclin-1-like protein isoform X2; XP_014479707.1), CeBeclin (Caenorhabditis elegans Beclin (human autophagy) homolog; CCD62215.1). 


\subsection{Developmental and Tissue-Specific Expression Patterns of TmAtg6}

The expression levels of TmAtg6 transcripts at different developmental stages and tissues were analyzed by qRT-PCR (Figure 3A). TmAtg6 transcripts were detected through all developmental stages and in all examined tissues. The highest expression level was observed in pupal stages, specifically in six-day-old pupae. Comparatively lower TmAtg6 transcript levels were observed in young and late instar larvae, 7-day-old pupae, and 1-day-old adults.

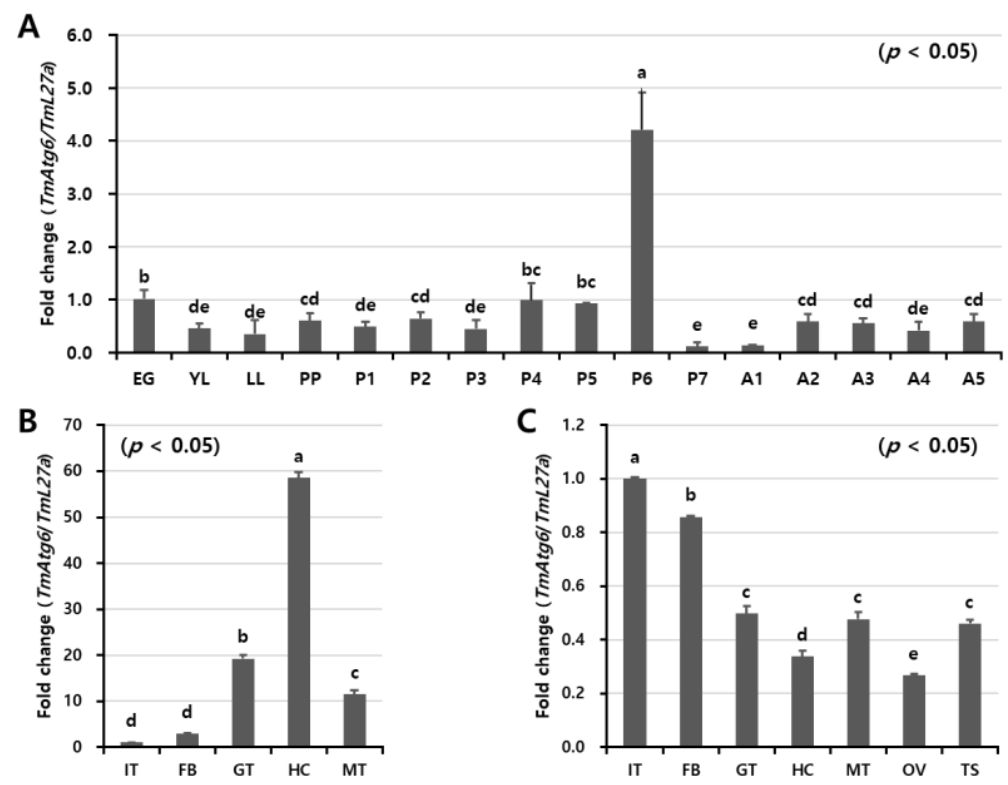

Figure 3. Developmental and tissue-specific expression patterns of TmAtg6 gene. (A) The developmental stages of mealworm, egg (EG), young larvae (YL), late larvae (LL), pre-pupa (PP), 1-7-days old pupae (P1-P7), and 1-5-days old adult (A1-A5), were examined to study the expression level of TmAtg6. For each stage, 20 individuals were used to extract RNA with the subsequent synthesis of cDNA. The results indicate that TmAtg6 expression was gradually increased from young larvae to 2-days old pupae with highest expression at the 6-days old pupal stage. In adult stages, there was no considerable expression difference. Tissue-specific expression patterns of TmAtg6 genes in late larvae (B) and in 5-day-old adults (C). Hemocytes, gut, fat body, Malpighian tubules, and integument (for late instar larvae and adults), and testes and ovaries (for adults) were dissected and collected from a total of 20 late larvae and 5-day-old adults. The results indicate that TmAtg6 was highly expressed in hemocytes, while low expression was observed in the integument and fat body in late larvae. In adults, the expression levels of TmAtg6 were high in fat body and integument. IT; integument, GT; gut, FB; fat body, HC; hemocytes, MT; Malpighian tubules, OV; ovary, and TS; testis. Tenebrio ribosomal protein 27a (TmL27a) was used as internal control.

In the tissues, the highest TmAtg6 expression levels were observed in the hemocytes of late larvae and the integument and fat body of adults (Figure 3B,C). Conversely, TmAtg6 expression levels were low in the integument of late larvae and the hemocytes of adults.

\subsection{Temporal Induction Pattern of TmAtg6}

To investigate the inducibility of the TmAtg6 gene, E. coli, S. aureus, L. monocytogenes, or C. albicans were injected into T. molitor larvae and the three immune tissues such as hemocytes, fat body, and gut were time-dependently (at 3, 6, 9, 12, and $24 \mathrm{~h}$ post-injection) collected for the analysis of the induction pattern by qRT-PCR. Remarkably, TmAtg 6 mRNA was highly induced by L. monocytogenes in all tissues (Figure 4), whereas E. coli, S. aureus, and C. albicans slightly induce TmAtg6 mRNA. In hemocytes, the induction of TmAtg 6 by L. monocytogenes showed the highest expression at $9 \mathrm{~h}$ post-injection. In the 
gut, $\operatorname{TmAtg} 6$ expression was represented in two patterns, being highly expressed at $3 \mathrm{~h}$ post-injection, slightly expressed at 6 and $9 \mathrm{~h}$ post-injection, and increased again at $12 \mathrm{~h}$ post-injection. In the fat body, the highest expression of TmAtg 6 was detected at 3 and $12 \mathrm{~h}$ post-injection of L. monocytogenes.
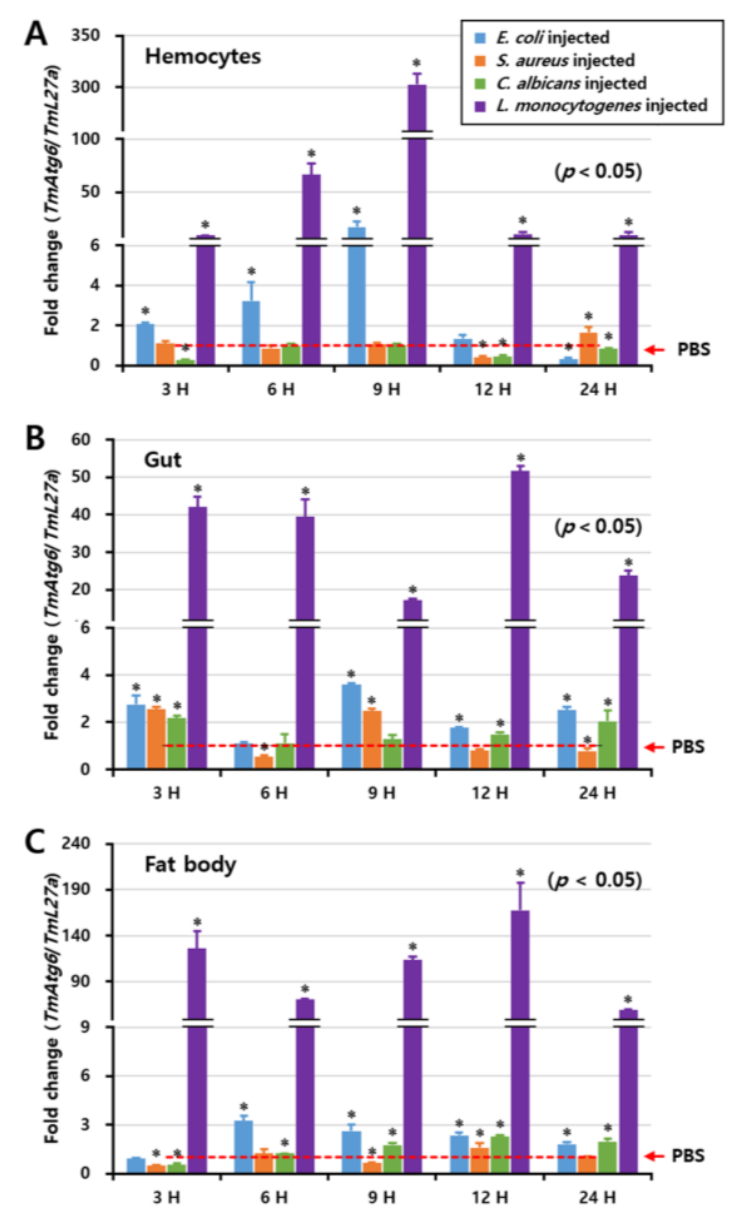

Figure 4. Induction patterns of TmAtg6 in different tissues against E. coli, S. aureus, C. albicans, and L. monocytogenes, including hemocytes (A), gut (B), and fat body (C). The induction pattern analysis of TmAtg6 gene in different tissues of T. molitor young larvae was performed by injection of E. coli $\left(10^{6}\right.$ cells $\left./ \mu \mathrm{L}\right)$, S. aureus $\left(10^{6}\right.$ cells $\left./ \mu \mathrm{L}\right)$, C. albicans $\left(5 \times 10^{4}\right.$ cells $\left./ \mu \mathrm{L}\right)$, or L. monocytogenes $\left(10^{6}\right.$ cells/ $\left.\mu \mathrm{L}\right)$. Samples were collected at different time points such as $3,6,9,12$, and $24 \mathrm{~h}$ post-injection of microorganisms. Twenty young larvae of mealworm were used at each time point. In hemocytes, TmAtg6 gene was highly induced at $9 \mathrm{~h}$ post-injection of L. monocytogenes. In the gut, the injection of L. monocytogenes highly induced the expression of TmAtg 6 at $3 \mathrm{~h}$ post-injection, gradually decreased during 6 and $9 \mathrm{~h}$, and then highly induced levels of TmAtg $612 \mathrm{~h}$ post-injection. In the fat body, injection of L. monocytogenes highly induced TmAtg6 at $12 \mathrm{~h}$ post-infection.

\subsection{Effect of TmAtg6 RNAi on T. molitor Survivability}

To characterize the function of TmAtg6 against microorganisms, we silenced its transcript levels using RNAi and challenged T. molitor larvae with prepared microorganisms. The percentage of TmAtg6 downregulation was confirmed ( $84 \%$ knockdown) by qRT-PCR prior to microbial challenge. The survivability of the TmAtg6-silenced T. molitor larvae against microbial injection was monitored for 10 days. The injection of dsTmAtg6 and/or dsEGFP did not affect the survival of T. molitor larvae when injected with the control PBS. Compared to the dsEGFP-injected larval group, no significant difference was detected in the dsTmAtg6-injected group on larval survivability against any of the tested microorganisms except L. monocytogenes (Figure 5). Surprisingly, TmAtg6-silenced larvae showed higher susceptibility against $L$. monocytogenes compared to the dsEGFP group. 

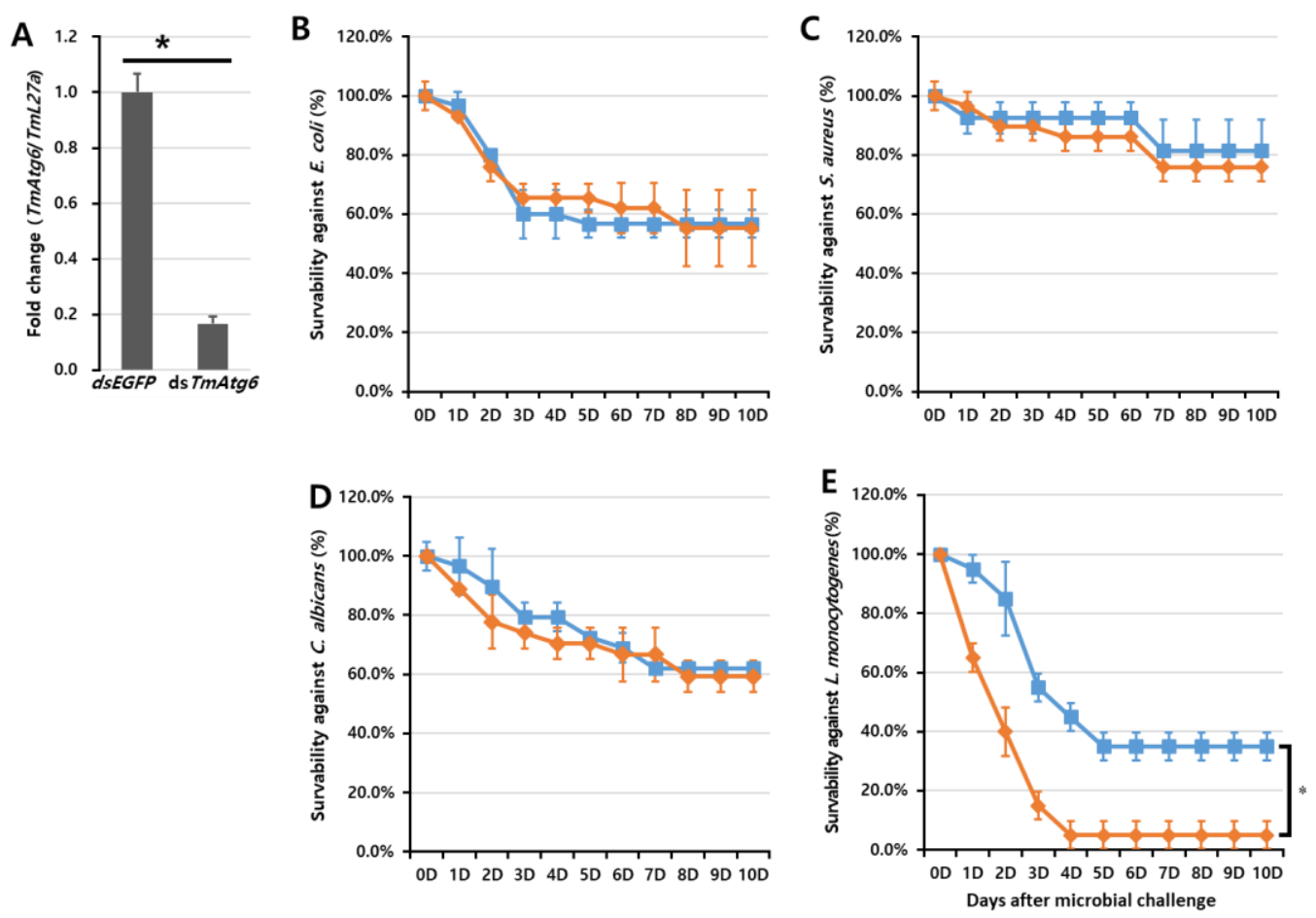

Figure 5. RNA interference (RNAi)-based functional study of TmAtg6 in Tenebrio molitor larvae. Larval survival curves following infection with microorganisms. TmAtg6 knockdown (A), E. coli (B), S. aureus (C), C. albicans (D), L. monocytogenes (E). * significant at $p<0.05$. Results represent the average of three independent replicates with standard error. TmAtg6 gene silencing significantly affected the survivability of T. molitor larvae against L. monocytogenes infection. In contrast, the TmAtg6 gene silencing did not show significant differences in survivability against E. coli, S. aureus, and C. albicans.

\section{Discussion}

Autophagy 6 (Beclin 1 in mammalian), as a key regulator of autophagy [24], has many functions in intracellular processes such as signaling pathways, vacuolar protein sorting [25], endocytic trafficking, apoptosis [26], and degradation of sequestered cytoplasmic contents, including damaged organelles and pathogens $[27,28]$. Additionally, crosstalk between autophagy and antiviral immunity has been reported, suggesting the dual effect of autophagy as promoting the clearance of viral components and activating the immune system to produce antiviral cytokines [29]. Therefore, Atg6 is an essential gene required for both development and host immunity. Specifically, the induction of autophagy (autophagosome formation) in mammals mainly depends on the Class III PI3K complex, comprising hVps34, Beclin-1, p150, and Atg14-like protein or ultraviolet irradiation resistance-associated gene (UVRAG) [30]. Similarly, in yeast, complex I (Vps15-Vps34-Vps30/Atg6-Atg14) and complex II (Vps15-Vps34-Vps30/Atg6-Atg14-Vps38) are required in autophagy and vascular protein sorting, respectively $[13,30]$. Thus, the current study was conducted to characterize the immune functions of TmAtg6 in T. molitor.

During the development and metamorphosis of holometabolous insects, cell death occurs at each stage, and the mechanisms of cell debris removal are essential in many aspects [31]. Therefore, the roles of autophagy in development and the clearance of invading pathogens have been extensively investigated [32-35]. For instance, autophagy occurs during the remodeling and degeneration of various larval tissues [36,37], as well as during changes in larval instars and larva-pupa transition [36,38]. Our observations regarding TmAgt6 expression in different developmental stages and tissues also suggest its importance in the growth and development of T. molitor. In particular, the highest expression of TmAtg6 in 6-day-old pupae may suggest that autophagy occurs during metamorphosis from pupae to adults. Likewise, the function of autophagy during metamorphic transition has been well characterized 
in Heliothis virescens [39] and Alabama argillacea [40]. Additionally, in the silkworm, Bombyx mori, the expression levels of several Atg genes including BmAtg1, -2, -6, -11, -12, -13, and -18 were high during molting and pupation stages when levels of the steroid hormone (20-hydroxyecdysone; 20E) were high [41]. Similarly, in T. molitor, the TmAtg8, -5, -3, and -13 transcripts were expressed in all tissues, suggesting their importance in the cell remodeling process and development $[17,18,42]$. Moreover, the expression of TmAtg6 in the hemocytes of T. molitor larvae suggests the function of TmAtg6 in insect development. Hemocytes have been reported as vital components in the synthesis and transport of nutrients and hormones for proper growth and development and in wound healing by clearance of dead cells through phagocytosis and autophagy [43,44].

Studies show that autophagy plays an important role in not only developmental functions, but also in immunological functions such as bacterial, viral, and parasitoid clearance. In mosquitoes, the autophagy pathway is relevant to the replication and transmission of arboviruses [45-47]. However, in other insect species, it has been reported that autophagy is induced and is crucial for the innate cellular immune response against several intracellular bacterial, fungal, and viral pathogens [48-50]. Additionally, the involvement of granulocyte-associated autophagy in hemocytes was immunologically and morphologically studied, showing a high accumulation of autophagic vacuoles in activated hemocytes granulocytes [51]. For example, in Drosophila, studies on the importance of antiviral autophagy against Rift Valley fever virus and Vesicular stomatitis virus revealed that viral replication was increased in the absence of autophagy genes [52,53]. Moreover, the pattern-recognition receptor, Peptidoglycan-recognition protein LE (PGRP-LE), was identified as a recognition protein of the diaminopimelic acid-type peptidoglycan derived from Gram-negative bacteria to induce autophagy, consequently preventing the growth of L. monocytogenes and promoting host survivability [54]. Our current induction studies also revealed that $\operatorname{TmAtg} 6$ is highly expressed in all tissues exclusively infected with L. monocytogenes. TmAtg6 is comparatively highly expressed in hemocytes. Supporting this result, Bénédicte and his colleagues reported that autophagy targets L. monocytogenes during primary infection to limit the onset of early bacterial growth [49]. Interestingly, TmAtg6 expression was particularly downregulated by E. coli, S. aureus, and C. albicans at different time points. Supporting our current finding, in the mammalian model, some microorganisms downregulate ATG genes to avoid antimicrobial autophagy [55]. This downregulation is achieved through the modification of phagosomes by blocking their maturation via fusion with autophagosomes [56]. Additionally, in insects, autophagy-associated genes are downregulated by Wolbachia through the suppression of the autophagic signal to prevent their elimination [57].

Moreover, we studied the function of TmAtg6 in the defense response against microbial infection by silencing TmAtg6 protein expression. The gene-silenced larval group showed significant susceptibility to L. monocytogenes infection, indicating that TmAtg6 is directly involved in counteracting intracellular pathogen infection in the mealworms. The previous studies also reported that the other autophagy-related genes are involved in the defense response to L. monocytogenes (TmAtg3, TmAtg5, Tmatg8) [17,18], E. coli, and S. aureaus (TmAtg13) [42]. Collectively, TmAtg6 plays an important role in the autophagy-dependent defense response against the intracellular pathogen L. monocytogenes in T. molitor.

\section{Materials and Methods}

\subsection{Insect Rearing and Maintenance}

The coleopteran insect, Tenebrio molitor (mealworm), was maintained at $27 \pm 1{ }^{\circ} \mathrm{C}$ and $60 \% \pm 5 \%$ relative humidity in the dark with an artificial diet prepared from $170 \mathrm{~g}$ of whole-wheat flour, $20 \mathrm{~g}$ of fried bean powder, $10 \mathrm{~g}$ of soy protein, $100 \mathrm{~g}$ of wheat bran, $200 \mathrm{~mL}$ of sterile water, $0.5 \mathrm{~g}$ of chloramphenicol, $0.5 \mathrm{~g}$ of sorbic acid, and $0.5 \mathrm{~mL}$ of propionic acid. For the experiments, the 10 to 12 instar larvae were used. To ensure uniformity in size, the larvae were separated according to their physical size using a set of laboratory test sieves (Pascall Eng. Co. Ltd, Crawley, Sussex, England). 


\subsection{Preparation of Microorganisms}

The following microorganisms were used in this study: Gram-negative bacteria (Escherichia coli K12), Gram-positive bacteria (Staphylococcus aureus RN4220 and Listeria monocytogenes), and fungi (Candida albicans). The microorganisms were cultured in Luria-Bertani (LB; E. coli and S. aureus), Sabouraud dextrose (C. albicans), and brain heart infusion (BHI; L. monocytogenes) broths at $37^{\circ} \mathrm{C}$ overnight and subcultured at $37^{\circ} \mathrm{C}$ for $3 \mathrm{~h}$. Then the microorganisms were harvested and washed 2 times by centrifugation at $3500 \mathrm{rpm}$ for $10 \mathrm{~min}$ in phosphate-buffered saline (PBS; pH 7.0). They were then suspended in PBS and the concentrations were measured at $\mathrm{OD}_{600}$. Finally, $10^{6}$ cells $/ \mu \mathrm{L}$ of $E$. coli, S. aureus, and L. monocytogenes and $5 \times 10^{4}$ cells $/ \mu \mathrm{L}$ of $C$. albicans were injected separately.

\subsection{Identification and Cloning of Full-Length cDNA Sequence of TmAtg6}

The T. molitor Atg6 gene was identified by local-blastn analysis (National Center for Biotechnology Information) with the amino acid sequence of the T. castaneum Atg6 gene (EFA06871.2) as the query search. The partial cDNA sequence of TmAtg6 was obtained from T. molitor RNAseq database and the full-length cDNA sequence of TmAtg6 (MN259540) was identified by 5' - and 3'-rapid amplification of cDNA end (RACE) PCR using a SMARTer RACE cDNA amplification kit (Clontech Laboratories, Mountain View, USA) according to the manufacturer's instructions. PCR was performed using the AccuPower ${ }^{\circledR}$ PyroHotStart Taq PCR PreMix (Bioneer, Deajeon, Korea) with TmAtg6 specific primers (RACE primers included TmAtg6 -cloning_Fw and TmAtg6 -cloning_Rv; Table 1). PCR was carried out under the following conditions: Pre-denaturation at $95^{\circ} \mathrm{C}$ for $5 \mathrm{~min}$, followed by 35 cycles of denaturation at $95^{\circ} \mathrm{C}$ for $30 \mathrm{~s}$, annealing at $53{ }^{\circ} \mathrm{C}$ for $30 \mathrm{~s}$, and extension at $72{ }^{\circ} \mathrm{C}$ for $2 \mathrm{~min}$, and a final extension at $72{ }^{\circ} \mathrm{C}$ for 5 min using a MyGenie96 Thermal Block (Bioneer, Deajeon, Korea). PCR products were purified using an AccuPrep ${ }^{\circledR}$ PCR Purification Kit (Bioneer, Deajeon, Korea), immediately ligated into T-Blunt vectors (Solgent, Deajeon, Korea), and transformed into DH5 $\alpha$ competent cells according to the manufacturer's instructions. Plasmid DNA was extracted from fully grown competent cells using an AccuPrep ${ }^{\circledR}$ Nano-Plus Plasmid Extraction Kit (Bioneer, Deajeon, Korea), sequenced, and analyzed. Finally, the full-length cDNA sequence of $\operatorname{TmAtg} 6$ was obtained.

Table 1. Sequences of the primers used in this study.

\begin{tabular}{|c|c|}
\hline Name & Primers sequence \\
\hline TmAtg6_qRTPCR_Fw & 5'-AGCTCCaTGTCGTTTGTTCG-3' \\
\hline TmAtg6-qRTPCR-Rv & 5'-GGTGGTCAATGTTTGAGTTGCC-3' \\
\hline TmAtg6-T7_Fw & 5'-TAATACGACTCACTATAGGGT AGCTCCATGTCGTTTGTTCG-3' \\
\hline TmAtg6-T7-Rv & 5'-TAATACGACTCACTATAGGGT GTCAATGTTTGAGTTGCC-3' \\
\hline TmBeclin1 5'RACE GSP1 & 5'-TGTGAACACCTTTGGCACAT-3' \\
\hline TmBeclin1 5'RACE GSP2 & 5'-CACACAAAGGGTGGTCAATG-3' \\
\hline TmBeclin1 3'RACE GSP1 & 5'-GAAATTGGAAAAGGGCAACA-3' \\
\hline TmBeclin1 3'RACE GSP2 & 5'-TGCTCTGTTGCTCTCTGCTC-3' \\
\hline TmL27a_qPCR_Fw & 5'-TCATCCTGAAGGCAAAGCTCCAGT-3' \\
\hline TmL27a_qPCR_Rv & 5'-AGGTTGGTTAGGCAGGCACCTTTA-3' \\
\hline dsEGFP_Fw & 5'-TAATACGACTCACTATAGGGT CGTAAACGGCCACAAGTTC-3' \\
\hline dsEGFP_Rv & $5^{\prime}$-TAATACGACTCACTATAGGGT TGCTCAGGTAGTGTTGTCG-3' \\
\hline
\end{tabular}

\subsection{Domain Analysis and Phylogenetic Analysis}

Specific domains were analyzed using the InterProScan 5 and blastp programs [58,59]. Multiple alignments were performed with representative Atg6 protein sequences of other insects obtained from Genbank using Clustal X2 software [60]. Phylogenetic and percentage identity analyses were conducted using Clustal X2 and MEGA 7 programs [61]. The amino acid sequences of CeBeclin of Rhabditida were used as outgroups. 


\subsection{Expression Analysis of TmAtg6}

Whole-body samples were collected from T. molitor $(n=20)$ at various developmental stages, including the eggs (EG), young instar larvae (YL; 10th-12th instar larvae), late instar larvae (LL; 19th-20th instar larvae), prepupae (PP), 1 to 7-day-old pupae (P1-P7), and 1 to 5-day-old adults (A1-A5). To investigate tissue-specific TmAtg6 expression patterns, samples were collected from various tissues $(n=20)$, including the gut, hemocytes, integument, Malpighian tubules, and fat body of late instar larvae and 5-day-old adults, and the ovaries and testes of the adults. In addition, tissue-specific induction pattern analysis of the TmAtg6 gene was performed by injecting E. coli, $S$. aureus, L. monocytogenes, or C. albicans. Three well-known immune tissues such as hemocytes, fat body, and gut were dissected and collected at 3, 6, 9, 12, and $24 \mathrm{~h}$ post-injection. Samples were collected in $500 \mu \mathrm{L}$ of guanidine thiocyanate RNA lysis buffer $(2 \mathrm{~mL}$ of $0.5 \mathrm{M}$ EDTA, $1 \mathrm{~mL}$ of $1 \mathrm{M}$ 2-( $\mathrm{N}$-morpholino)ethanesulfonic acid (MES) Buffer, $17.72 \mathrm{~g}$ of guanidine thiocyanate, $0.58 \mathrm{~g}$ of sodium chloride, $0.7 \mathrm{mg}$ of phenol red, $25 \mu \mathrm{L}$ of Tween-80, $250 \mu \mathrm{L}$ of acetic acid glacial, and $500 \mu \mathrm{L}$ of isoamyl alcohol) and homogenized using a homogenizer (Bertin Technologies, Montigny-le-Bretonneux, France) at $7500 \mathrm{rpm}$ for $20 \mathrm{~s}$.

Total RNAs were extracted from the collected samples using the modified LogSpin RNA isolation method [62]. Briefly, the homogenized samples were centrifuged for $5 \mathrm{~min}$ at $13,000 \mathrm{rpm}$ and $4{ }^{\circ} \mathrm{C}$. The supernatant $(300 \mu \mathrm{L})$ was transferred into a new $1.5 \mathrm{~mL}$ tube, mixed with 1 volume of pure ethanol, transferred into a silica spin column (Bioneer, Missouri City, Texas, USA, KA-0133-1), and centrifuged for $30 \mathrm{~s}$ at $13,000 \mathrm{rpm}$ and $4{ }^{\circ} \mathrm{C}$. The silica spin column was treated with DNase (Promega, Deajeon, Korea, M6101) at $25^{\circ} \mathrm{C}$ for $15 \mathrm{~min}$ and washed with $3 \mathrm{M}$ sodium acetate buffer and $80 \%$ ethanol. After drying by centrifugation for $2 \mathrm{~min}$ at $13,000 \mathrm{rpm}$ and $4{ }^{\circ} \mathrm{C}$, total RNAs were eluted with $30 \mu \mathrm{L}$ of distilled water (Sigma, USA, W4502-1L). cDNAs were immediately synthesized with $2 \mu \mathrm{g}$ of total RNAs using an AccuPower ${ }^{\circledR}$ RT PreMix (Bioneer, Deajeon, Korea) and Oligo (dT) 12-18 primers on a MyGenie96 Thermal Block (Bioneer, Deajeon, Korea) according to the manufacturer's instructions.

Quantitative real-time PCR (qRT-PCR) reactions were performed using an Exicycler ${ }^{\mathrm{TM}} 96$ Real-Time Quantitative Thermal Block (Bioneer Company, Daejeon, Korea) with a gene-specific primers and AccuPower ${ }^{\circledR} 2 X$ GreenStar qPCR Master Mix (Bioneer, Deajeon, Korea) under the following conditions: Initial denaturation at $94{ }^{\circ} \mathrm{C}$ for $5 \mathrm{~min}, 45$ cycles of denaturation at $9{ }^{\circ} \mathrm{C}$ for $15 \mathrm{~s}$, and annealing at $60{ }^{\circ} \mathrm{C}$ for $30 \mathrm{~s}$. The $2^{-\Delta \Delta \mathrm{Ct}}$ method [63] was employed to analyze TmAtg 6 expression levels. T. molitor ribosomal protein $\mathrm{L} 27 \mathrm{a}$ ( $\mathrm{TmL} 27 a)$ was used as an internal control to normalize differences in template concentration between samples.

\section{6. $\operatorname{TmAtg} 6$ Gene Silencing}

cDNA synthesized from T. molitor hemocytes was amplified by semi-quantitative PCR using TmAtg6 gene-specific primers (product size; $500 \mathrm{bp}$, listed in Table 1) conjugated with a T7 promoter sequence designed using SnapDragon software (http://www.flyrnai.org/cgi-bin/RNAi_find_primers.pl). The PCR reaction was carried out under the following conditions: Initial denaturation at $94{ }^{\circ} \mathrm{C}$ for $2 \mathrm{~min}$ followed by 35 cycles of denaturation at $94^{\circ} \mathrm{C}$ for $30 \mathrm{~s}$, annealing at $53^{\circ} \mathrm{C}$ for $30 \mathrm{~s}$, extension at $72{ }^{\circ} \mathrm{C}$ for $30 \mathrm{~s}$, and a final extension at $72{ }^{\circ} \mathrm{C}$ for $5 \mathrm{~min}$. PCR products were purified using the AccuPrep PCR Purification Kit (Bioneer Company, Daejeon, South Korea), and dsRNA was synthesized using an Ampliscribe ${ }^{\mathrm{TM}}$ T7-Flash ${ }^{\mathrm{TM}}$ Transcription Kit (Epicentre Biotechnologies, Madison, WI, USA) according to the manufacturer's instructions. After synthesis, dsRNA was purified using $5 \mathrm{M}$ ammonium acetate and precipitated by $80 \%$ ethanol. Subsequently, it was quantified using an Epoch spectrophotometer (BioTek Instruments Inc, Winooski, VT, USA). As a control, we synthesized dsRNA for enhanced green fluorescent protein (dsTmEGFP) and stored at $-20^{\circ} \mathrm{C}$ until use.

The synthesized dsTmAtg 6 was diluted to a final concentration of $1.5 \mu \mathrm{g} / \mu \mathrm{L}$. dsRNA $(1.5 \mu \mathrm{g} / \mu \mathrm{L})$ was injected into young-instar larvae (10th-12th instars; $n=30$ ) using disposable needles mounted onto a micro-applicator (Picospiritzer III Micro Dispense System, Parker Hannifin, Hollis, NH, USA). Another set of young-instar larvae $(n=30)$ were injected with equal amounts of dsEGFP used as a 
negative control. Injected larvae were maintained on an artificial diet under standard rearing conditions. TmAtg 6 knockdown was evaluated and over 90\% of knockdown was achieved at 2 days post-injection.

\subsection{Survivability Assay}

E. coli $\left(10^{6}\right.$ cells $\left./ \mu \mathrm{L}\right)$, S. aureus $\left(10^{6}\right.$ cells $\left./ \mu \mathrm{L}\right)$, L. monocytogenes $\left(5 \times 10^{6}\right.$ cells $\left./ \mu \mathrm{L}\right)$, and $C$. albicans $(5 \times$ $10^{4}$ cells $/ \mu \mathrm{L}$ ) were prepared according to the protocol as described above. Bioassays were conducted by injecting $1.5 \mu \mathrm{g} / \mu \mathrm{L}$ dsTmAtg 6 into the hemocoel of young larvae. Two days post-injection, the knockdown level was confirmed by qRT-PCR, and prepared microorganisms were injected into both the dsTmAtg6 and dsEGFP-treated larval groups. The challenged larvae were maintained, and the number of living larvae was recorded for 10 days. The survival rates of the TmAtg6-silenced group were compared to those of the control groups. All the experiments were triplicated. Statistical analysis was conducted using SAS 9.4 software (SAS Institute Inc., Cary, NC, USA), and the cumulative survival ratios were analyzed by Tukey's multiple test at a significance level of $p<0.05$.

\section{Conclusions}

In this study, we identified and characterized the immunological function of TmAtg6 in T. molitor. The induction patterns of TmAtg6 in response to microbial challenges and survivability study confirmed that the TmAtg6 plays a key role against L. monocytogenes infection in T. molitor. We are now focusing on the characterization of the TmAtg6-Atg14L-Vps34-Vps15 complex in autophagosome formation in mealworms during the microbial challenge.

Supplementary Materials: Supplementary materials can be found at https://www.mdpi.com/1422-0067/21/4/1232/s1.

Author Contributions: Y.S.H. and Y.H.J. conceived and designed the experiments; T.T.E., M.K., K.B.P., J.H.C., Y.M.B. and B.K. performed the experiments; T.T.E. and Y.H.J. and analyzed the data; Y.S.H. and Y.H.J. contributed reagents/materials/analysis tools; T.T.E. wrote the manuscript; Y.H.J., Y.S.H. and Y.S.L. revised the manuscript. All authors have read and agreed to the published version of the manuscript.

Funding: This study was financially supported by Chonnam National University (Grant number: 2017-2919).

Conflicts of Interest: The authors declare no conflict of interest.

\section{References}

1. Mulakkal, N.C.; Nagy, P.; Takats, S.; Tusco, R.; Juhász, G.; Nezis, I.P. Autophagy in Drosophila: From historical studies to current knowledge. Biomed. Res. Int. 2014, 2014. [CrossRef]

2. Lum, J.J.; DeBerardinis, R.J.; Thompson, C.B. Autophagy in metazoans: Cell survival in the land of plenty. Nat. Rev. Mol. Cell Biol. 2005, 6, 439-448. [CrossRef]

3. Bryant, B.; Raikhel, A.S. Programmed autophagy in the fat body of Aedes aegypti is required to maintain egg maturation cycles. PLoS ONE 2011, 6, e25502. [CrossRef]

4. Yang, Y.P.; Liang, Z.Q.; Gu, Z.L.; Qin, Z.H. Molecular mechanism and regulation of autophagy 1. Acta Pharmacol. Sin. 2005, 26, 1421-1434. [CrossRef]

5. Kroemer, G.; Jäättelä, M. Lysosomes and autophagy in cell death control. Nat. Rev. Cancer 2005, 5, 886. [CrossRef]

6. Maiuri, M.C.; Zalckvar, E.; Kimchi, A.; Kroemer, G. Self-eating and self-killing: Crosstalk between autophagy and apoptosis. Nat. Rev. Mol. Cell Biol. 2007, 8, 741. [CrossRef]

7. Sharma, V.; Verma, S.; Seranova, E.; Sarkar, S.; Kumar, D. Selective Autophagy and Xenophagy in Infection and Disease. Front. Cell Dev. Biol. 2018, 6. [CrossRef]

8. Gatica, D.; Lahiri, V.; Klionsky, D.J. Cargo recognition and degradation by selective autophagy. Nat. Cell Biol. 2018, 20, 233. [CrossRef]

9. Shaid, S.; Brandts, C.; Serve, H.; Dikic, I. Ubiquitination and selective autophagy. Cell Death Differ. 2013, 20, 21. [CrossRef]

10. Mizushima, N. Autophagy: Process and function. Genes Dev. 2007, 21, 2861-2873. [CrossRef]

11. Kamada, Y.; Funakoshi, T.; Shintani, T.; Nagano, K.; Ohsumi, M.; Ohsumi, Y. Tor-mediated induction of autophagy via an Apg1 protein kinase complex. J. Cell Biol. 2000, 150, 1507-1513. [CrossRef] [PubMed] 
12. Pozuelo-Rubio, M. 14-3-3 Proteins are Regulators of Autophagy. Cells 2012, 1, 754-773. [CrossRef] [PubMed]

13. Kihara, A.; Noda, T.; Ishihara, N.; Ohsumi, Y. Two distinct Vps34 phosphatidylinositol 3-kinase complexes function in autophagy and carboxypeptidase Y sorting in Saccharomyces cerevisiae. J. Cell Biol. 2001, 152, 519-530. [CrossRef] [PubMed]

14. Nair, U.; Cao, Y.; Xie, Z.; Klionsky, D.J. Roles of the lipid-binding motifs of Atg18 and Atg21 in the cytoplasm to vacuole targeting pathway and autophagy. J. Biol. Chem. 2010, 285, 11476-11488. [CrossRef]

15. Noda, T.; Kim, J.; Huang, W.P.; Baba, M.; Tokunaga, C.; Ohsumi, Y.; Klionsky, D.J. Apg9p/Cvt7p is an integral membrane protein required for transport vesicle formation in the Cvt and autophagy pathways. J. Cell Biol. 2000, 148, 465-480. [CrossRef]

16. Geng, J.; Klionsky, D.J. The Atg8 and Atg12 ubiquitin-like conjugation systems in macroautophagy. 'Protein modifications: Beyond the usual suspects' review series. EMBO Rep. 2008, 9, 859-864. [CrossRef]

17. Tindwa, H.; Jo, Y.H.; Patnaik, B.B.; Noh, M.Y.; Kim, D.H.; Kim, I.; Han, Y.S.; Lee, Y.S.; Lee, B.L.; Kim, N.J. Depletion of autophagy-related genes Atg3 and Atg5 in Tenebrio molitor leads to decreased survivability against an intracellular pathogen, Listeria monocytogenes. Arch. Insect Biochem. Physiol. 2015, 88, 85-99. [CrossRef]

18. Tindwa, H.; Jo, Y.H.; Patnaik, B.B.; Lee, Y.S.; Kang, S.S.; Han, Y.S. Molecular cloning and characterization of autophagy-related gene TmATG8 in Listeria-invaded hemocytes of Tenebrio molitor. Dev. Comp. Immunol. 2015, 51, 88-98. [CrossRef]

19. Cao, Y.; Klionsky, D.J. Physiological functions of Atg6/Beclin 1: A unique autophagy-related protein. Cell Res. 2007, 17, 839. [CrossRef]

20. Kametaka, S.; Okano, T.; Ohsumi, M.; Ohsumi, Y. Apg14p and Apg6/Vps30p form a protein complex essential for autophagy in the yeast, Saccharomyces cerevisiae. J. Biol. Chem. 1998, 273, 22284-22291. [CrossRef]

21. Fujiki, Y.; Yoshimoto, K.; Ohsumi, Y. An Arabidopsis homolog of yeast ATG6/VPS30 is essential for pollen germination. Plant Physiol. 2007, 143, 1132-1139. [CrossRef] [PubMed]

22. Qu, X.; Yu, J.; Bhagat, G.; Furuya, N.; Hibshoosh, H.; Troxel, A.; Rosen, J.; Eskelinen, E.-L.; Mizushima, N.; Ohsumi, Y. Promotion of tumorigenesis by heterozygous disruption of the beclin 1 autophagy gene. J. Clin. Investig. 2003, 112, 1809-1820. [CrossRef] [PubMed]

23. Yue, Z.; Jin, S.; Yang, C.; Levine, A.J.; Heintz, N. Beclin 1, an autophagy gene essential for early embryonic development, is a haploinsufficient tumor suppressor. Proc. Natl. Acad. Sci. USA 2003, 100, 15077-15082. [CrossRef] [PubMed]

24. Liang, X.H.; Jackson, S.; Seaman, M.; Brown, K.; Kempkes, B.; Hibshoosh, H.; Levine, B. Induction of autophagy and inhibition of tumorigenesis by beclin 1. Nature 1999, 402, 672. [CrossRef]

25. Lawrence, B.P.; Brown, W.J. Autophagic vacuoles rapidly fuse with pre-existing lysosomes in cultured hepatocytes. J. Cell Sci. 1992, 102, 515-526. [PubMed]

26. Levine, B.; Klionsky, D.J. Development by self-digestion: Molecular mechanisms and biological functions of autophagy. Dev. Cell 2004, 6, 463-477. [CrossRef]

27. Klionsky, D.J. The autophagy connection. Dev. Cell 2010, 19, 11-12. [CrossRef]

28. Xie, Z.; Klionsky, D.J. Autophagosome formation: Core machinery and adaptations. Nat. Cell Biol. 2007, 9, 1102. [CrossRef]

29. Tian, Y.; Wang, M.-L.; Zhao, J. Crosstalk between autophagy and type I interferon responses in innate antiviral immunity. Viruses 2019, 11, 132. [CrossRef]

30. Funderburk, S.F.; Wang, Q.J.; Yue, Z. The Beclin 1-VPS34 complex-At the crossroads of autophagy and beyond. Trends Cell Biol. 2010, 20, 355-362. [CrossRef]

31. Nezis, I.P.; Vaccaro, M.I.; Devenish, R.J.; Juhász, G. Autophagy in development, cell differentiation, and homeodynamics: From molecular mechanisms to diseases and pathophysiology. Biomed. Res. Int. 2014, 2014. [CrossRef] [PubMed]

32. Berry, D.L.; Baehrecke, E.H. Growth arrest and autophagy are required for salivary gland cell degradation in Drosophila. Cell 2007, 131, 1137-1148. [CrossRef] [PubMed]

33. Denton, D.; Shravage, B.; Simin, R.; Mills, K.; Berry, D.L.; Baehrecke, E.H.; Kumar, S. Autophagy, not apoptosis, is essential for midgut cell death in Drosophila. Curr. Biol. 2009, 19, 1741-1746. [CrossRef] [PubMed]

34. Tettamanti, G.; Carata, E.; Montali, A.; Dini, L.; Fimia, G.M. Autophagy in development and regeneration: Role in tissue remodelling and cell survival. Eur. Zool. J. 2019, 86, 113-131. [CrossRef] 
35. Galluzzi, L.; Yamazaki, T.; Kroemer, G. Linking cellular stress responses to systemic homeostasis. Nat. Rev. Mol. Cell Biol. 2018, 19, 731-745. [CrossRef]

36. Romanelli, D.; Casartelli, M.; Cappellozza, S.; De Eguileor, M.; Tettamanti, G. Roles and regulation of autophagy and apoptosis in the remodelling of the lepidopteran midgut epithelium during metamorphosis. Sci. Rep. 2016, 6, 32939. [CrossRef]

37. Montali, A.; Romanelli, D.; Cappellozza, S.; Grimaldi, A.; de Eguileor, M.; Tettamanti, G. Timing of autophagy and apoptosis during posterior silk gland degeneration in Bombyx mori. Arthropod Struct. Dev. 2017, 46, 518-528. [CrossRef]

38. Tettamanti, G.; Grimaldi, A.; Pennacchio, F.; de Eguileor, M. Lepidopteran larval midgut during prepupal instar: Digestion or self-digestion? Autophagy 2007, 3, 630-631. [CrossRef]

39. Tettamanti, G.; Grimaldi, A.; Casartelli, M.; Ambrosetti, E.; Ponti, B.; Congiu, T.; Ferrarese, R.; Rivas-Pena, M.L.; Pennacchio, F.; De Eguileor, M. Programmed cell death and stem cell differentiation are responsible for midgut replacement in Heliothis virescens during prepupal instar. Cell Tissue Res. 2007, 330, 345-359. [CrossRef]

40. deSousa, M.E.C.; Wanderley-Teixeira, V.; Teixeira, Á.A.; deSiqueira, H.A.; Santos, F.A.; Alves, L.C. Ultrastructure of the Alabama argillacea (Hübner) (Lepidoptera: Noctuidae) midgut. Micron 2009, 40, 743-749. [CrossRef]

41. Tian, L.; Ma, L.; Guo, E.; Deng, X.; Ma, S.; Xia, Q.; Cao, Y.; Li, S. 20-Hydroxyecdysone upregulates Atg genes to induce autophagy in the Bombyx fat body. Autophagy 2013, 9, 1172-1187. [CrossRef] [PubMed]

42. Lee, J.H.; Jo, Y.H.; Patnaik, B.B.; Park, K.B.; Tindwa, H.; Seo, G.W.; Chandrasekar, R.; Lee, Y.S.; Han, Y.S. Cloning, expression analysis, and RNA interference study of a HORMA domain containing autophagy-related gene 13 (ATG13) from the coleopteran beetle, Tenebrio molitor. Front. Physiol. 2015, 6. [CrossRef]

43. Ling, E.; Shirai, K.; Kanekatsu, R.; Kiguchi, K. Hemocyte differentiation in the hematopoietic organs of the silkworm, Bombyx mori: Prohemocytes have the function of phagocytosis. Cell Tissue Res. 2005, 320, 535-543. [CrossRef] [PubMed]

44. Merchant, D.; Ertl, R.L.; Rennard, S.I.; Stanley, D.W.; Miller, J.S. Eicosanoids mediate insect hemocyte migration. J. Insect Physiol. 2008, 54, 215-221. [CrossRef] [PubMed]

45. Lee, Y.-R.; Lei, H.-Y.; Liu, M.-T.; Wang, J.-R.; Chen, S.-H.; Jiang-Shieh, Y.-F.; Lin, Y.-S.; Yeh, T.-M.; Liu, C.-C.; Liu, H.-S. Autophagic machinery activated by dengue virus enhances virus replication. Virology 2008, 374, 240-248. [CrossRef] [PubMed]

46. McLean, J.E.; Wudzinska, A.; Datan, E.; Quaglino, D.; Zakeri, Z. Flavivirus NS4A-induced autophagy protects cells against death and enhances virus replication. J. Biol. Chem. 2011, 286, 22147-22159. [CrossRef]

47. Abernathy, E.; Mateo, R.; Majzoub, K.; Van Buuren, N.; Bird, S.W.; Carette, J.E.; Kirkegaard, K. Differential and convergent utilization of autophagy components by positive-strand RNA viruses. PLoS Biol. 2019, 17, e2006926. [CrossRef]

48. Colombo, M.I.; Gutierrez, M.G.; Romano, P.S. The two faces of autophagy: Coxiella and Mycobacterium. Autophagy 2006, 2, 162-164. [CrossRef]

49. Py, B.F.; Lipinski, M.M.; Yuan, J. Autophagy limits Listeria monocytogenes intracellular growth in the early phase of primary infection. Autophagy 2007, 3, 117-125. [CrossRef]

50. Campoy, E.; Colombo, M.I. Autophagy in intracellular bacterial infection. Biochim. Biophys. Acta BBA Mol. Cell Res. 2009, 1793, 1465-1477. [CrossRef]

51. Kwon, H.; Bang, K.; Cho, S. Characterization of the hemocytes in larvae of Protaetia brevitarsis seulensis: Involvement of granulocyte-mediated phagocytosis. PLoS ONE 2014, 9, e103620. [CrossRef] [PubMed]

52. Moy, R.H.; Gold, B.; Molleston, J.M.; Schad, V.; Yanger, K.; Salzano, M.-V.; Yagi, Y.; Fitzgerald, K.A.; Stanger, B.Z.; Soldan, S.S.; et al. Antiviral autophagy restrictsRift Valley fever virus infection and is conserved from flies to mammals. Immunity 2014, 40, 51-65. [CrossRef] [PubMed]

53. Shelly, S.; Lukinova, N.; Bambina, S.; Berman, A.; Cherry, S. Autophagy is an essential component of Drosophila immunity against vesicular stomatitis virus. Immunity 2009, 30, 588-598. [CrossRef] [PubMed]

54. Yano, T.; Mita, S.; Ohmori, H.; Oshima, Y.; Fujimoto, Y.; Ueda, R.; Takada, H.; Goldman, W.E.; Fukase, K.; Silverman, N. Autophagic control of listeria through intracellular innate immune recognition in drosophila. Nat. Immunol. 2008, 9, 908. [CrossRef]

55. Butchar, J.P.; Cremer, T.J.; Clay, C.D.; Gavrilin, M.A.; Wewers, M.D.; Marsh, C.B.; Schlesinger, L.S.; Tridandapani, S. Microarray analysis of human monocytes infected with Francisella tularensis identifies new targets of host response subversion. PLoS ONE 2008, 3, e2924. [CrossRef] 
56. Amer, A.O.; Swanson, M.S. Autophagy is an immediate macrophage response to Legionella pneumophila. Cell. Microbiol. 2005, 7, 765-778. [CrossRef]

57. Zug, R.; Hammerstein, P. Wolbachia and the insect immune system: What reactive oxygen species can tell us about the mechanisms of Wolbachia-host interactions. Front. Microbiol. 2015, 6. [CrossRef]

58. Zdobnov, E.M.; Apweiler, R. InterProScan-an integration platform for the signature-recognition methods in InterPro. Bioinformatics 2001, 17, 847-848. [CrossRef]

59. Jones, P.; Binns, D.; Chang, H.Y.; Fraser, M.; Li, W.; McAnulla, C.; McWilliam, H.; Maslen, J.; Mitchell, A.; Nuka, G.; et al. InterProScan 5: Genome-scale protein function classification. Bioinformatics 2014, 30, 1236-1240. [CrossRef]

60. Larkin, M.A.; Blackshields, G.; Brown, N.P.; Chenna, R.; McGettigan, P.A.; McWilliam, H.; Valentin, F.; Wallace, I.M.; Wilm, A.; Lopez, R.; et al. Clustal W and Clustal X version 2.0. Bioinformatics 2007, 23, 2947-2948. [CrossRef]

61. Kumar, S.; Stecher, G.; Tamura, K. MEGA7: Molecular evolutionary genetics analysis version 7.0 for bigger datasets. Mol. Biol. Evol. 2016, 33, 1870-1874. [CrossRef] [PubMed]

62. Yaffe, H.; Buxdorf, K.; Shapira, I.; Ein-Gedi, S.; Moyal-Ben Zvi, M.; Fridman, E.; Moshelion, M.; Levy, M. LogSpin: A simple, economical and fast method for RNA isolation from infected or healthy plants and other eukaryotic tissues. BMC Res. Notes 2012, 5, 45. [CrossRef] [PubMed]

63. Livak, K.J.; Schmittgen, T.D. Analysis of relative gene expression data using real-time quantitative PCR and the 2- $\Delta \Delta$ CT method. Methods 2001, 25, 402-408. [CrossRef] [PubMed]

(C) 2020 by the authors. Licensee MDPI, Basel, Switzerland. This article is an open access article distributed under the terms and conditions of the Creative Commons Attribution (CC BY) license (http://creativecommons.org/licenses/by/4.0/). 